\title{
Epsilon-aminocaproic Acid for Treatment of Fibrinolysis during Liver Transplantation
}

\author{
Yoogoo Kang, M.D.," Jessica H. Lewis, M.D.,† Ashok Navalgund, M.D.," Michael W. Russell, M.D.," \\ Franklin A. Bontempo, M.D., Lawrence S. Niren, M.D.," Thomas E. Starzl, M.D., Ph.D.§
}

In 97 adult patients receiving liver transplants, the coagulation system was monitored by thrombelastography and by coagulation profile including PT; a PTT; platelet count; level of factors I, II, V, VII, VIII, IX, X, XI, and XII; fibrin degradation products; ethanol gel test; protamine gel test; and euglobulin lysis time. Preoperatively, fibrinolysis defined as a whole blood clot lysis index of less than $80 \%$ was present in 29 patients $(29.9 \%$ ), and a euglobulin lysis time of less than $1 \mathrm{~h}$ was present in 13 patients. Fibrinolysis increased progressively during surgery in 80 patients $(82.5 \%)$ and was most severe on reperfusion of the graft liver in 33 patients $(34 \%)$. When whole blood clot lysis $(\mathrm{F}<180 \mathrm{~min}$ ) was observed during reperfusion of the graft liver, blood coagulability was tested by thrombelastography using both a blood sample treated in vitro with 6 -aminocaproic acid $(0.09 \%)$ and an untreated sample. Blood treated with $\leftarrow$-aminocaproic acid showed improved coagulation without fibrinolytic activity in all 74 tests. When whole blood clot lysis time was less than $120 \mathrm{~min}$, generalized oozing occurred, and the effectiveness of aminocaproic acid was demonstrated in vitro during the pre-anhepatic and post-anhepatic stages, $t$-aminocaproic acid $(1 \mathrm{~g}$, single intravenous dose) was administered. In all 20 patients treated with 6 aminocaproic acid, fibrinolytic activity disappeared; whole blood clot lysis was not seen on thrombelastography during a 5-h observation period, and whole blood clot lysis index improved from 28.5 $\pm 29.5 \%$ to $94.8 \pm 7.4 \%$ (mean $\pm \mathrm{SD}, P<0.001)$. None of the treated patients had hemorrhagic or thrombotic complications. In patients undergoing liver transplantation, the judicious use of a small dose of $\in$-aminocaproic acid, when its efficacy was confirmed in vitro, effectively treated the severe fibrinolysis without clinical thrombotic complications. (Key words: Blood: coagulation; fibrinolysis. Liver: transplantation. Measurement techniques: thrombelastography. Pharmacology: (-aminocaproic acid.)

ORTHOTOPIC LIVER TRANSPLANTATION is frequently associated with surgical bleeding that requires massive blood transfusion. ${ }^{1}$ The surgical bleeding is compounded by preexisting coagulopathy, dilutional coagulopathy, fibrinolysis, and, possibly, disseminated intravascular coagulation. ${ }^{2}$ In a recent series of patients undergoing liver transplantation, the degree of coagulopathy and volume of transfusion decreased with the introduction of replacement therapy guided by the frequent thrombelastographic

* Assistant Professor, Department of Anesthesiology.

† Professor, Department of Medicine.

¥ Assistant Professor, Department of Medicine.

Professor, Department of Surgery.

Received from the Departments of Anesthesiology, Medicine, and Surgery, University of Pittsburgh School of Medicine, Pittsburgh, Pennsylvania. Accepted for publication January 18, 1986. Dr. Russell's current address is Medical College of Virginia, Richmond, Virginia.

Address reprint requests to Dr. Kang. Department of Anesthesiology, Presbyterian-University Hospital, Desoto \& O'Hara Streets, Pittsburgh, Pennsylvania 15213. monitoring of the coagulation system and the use of heparin-coated veno-venous bypass. ${ }^{3,4}$ However, active fibrinolysis, manifest as generalized oozing from a previously dry surgical field and unresponsive to replacement therapy, has been a major difficulty in the intraoperative management of liver transplantation.

Since the early experience in hepatic transplantation, activation of the fibrinolytic system has been recognized, ${ }^{5,6}$ and, although antifibrinolytic treatment appears beneficial, it has been used only sporadically. Von Kaulla et al., on the basis of postoperative thrombotic complications in patients with hepatic neoplasms, suggested that administration of $\epsilon$-aminocaproic acid (EACA) might be harmful in transient fibrinolysis, ${ }^{6}$ whereas Flute $e t$ al. suggested a possible beneficial role of EACA in patients receiving liver transplants. ${ }^{7}$ Thus far, antifibrinolytic therapy has been empirical; its indications have been ill defined, monitoring of fibrinolysis has been inadequate, and, usually, a large dose of EACA has been used in cases of uncontrolled bleeding. We designed the present study to investigate the significance of fibrinolysis, to evaluate the clinical effectiveness of EACA, and to identify a clinically effective dose of EACA in patients receiving liver transplants.

\section{Methods}

After the study protocol was approved by the Institutional Review Board for Biomedical Research at the University of Pittsburgh, adult patients undergoing liver transplantation between October 1983 and January 1985 were observed prospectively. Two 8.5-French indwelling catheters were inserted for volume infusion, one in the antecubital vein, and another in the external or internal jugular vein. In addition, a flow-directed pulmonary artery catheter with on-line oximetry was inserted via the right internal jugular vein, and two indwelling intraarterial catheters were placed in the radial arteries, one for pressure monitoring, and one for blood sampling and back-up pressure monitoring. A heparin-coated veno-venous bypass system (Biomedicus Inc., Minnetonka, MN) was used in all patients during the anhepatic stage. A rapid-infusion system ${ }^{8}$ was used to replace lost blood volume with a fixed fluid composition of packed red blood cells (RBC), fresh frozen plasma (FFP), and electrolyte solution (Plasma-lyte $\mathrm{A}^{\bullet}$, Travenol Laboratories Inc., Deerfield, IL 60015) in a ratio of 300:200:250 ml. FFP was added to prevent dilutional coagulopathy. The blood 
mixture yielded levels of: fibrinogen, $130 \mathrm{mg} \%$; factor II, $0.59 \mathrm{U} / \mathrm{ml}$; factor $\mathrm{V}, 0.21 \mathrm{U} / \mathrm{ml}$; and factor VIII, $0.57 \mathrm{U} / \mathrm{ml}$. Electrolyte solution was added to decrease hematocrit to $27 \pm 2 \%$, to reduce the loss of $\mathrm{RBC}$, and to improve circulatory rheology. Transfusion of additional blood components was guided by variables measured by thrombelastography (TEG): 2 units of fresh frozen plasma were given when reaction time was longer than $15 \mathrm{~min}$, 10 units of platelets when maximum amplitude was less than $40 \mathrm{~mm}$, and 6 units of cryoprecipitate when clot formation rate was persistently less than $40^{\circ}$.

TEG is shown schematically in figure 1 . The device consists of a highly polished stainless steel cup that contains whole blood $(0.36 \mathrm{ml})$ and a pin freely suspended by a torsion wire. The temperature of the cup is kept at $37^{\circ}$ C. It oscillates on its vertical axis of $4.45^{\circ}$ every 9 s. Initially, blood injected into the cup remains fluid, and the oscillation of the cup is not transmitted to the pin. As fibrin strands form between the surfaces of the cup and the pin, the shear elasticity of fibrin strands increases, and the motion of the cup is coupled to the pin. The motion of the pin, in turn, is transmitted to the torsion wire and recorded on thermal paper. Therefore, TEG monitors the entire process of coagulation, including the initial fluid state without fibrin strands, the gradual increase in strength of fibrin strands (coagulation), and the resolution of fibrin strands (fibrinolysis). The variables measured by TEG are: reaction time $(r$ [min]), coagulation time $(r+k$ [min]), clot formation rate $\left(\alpha\left[^{\circ}\right]\right)$, maximum amplitude (MA [mm]), amplitude 60 min after maximum amplitude $\left(A_{60}[\mathrm{~mm}]\right.$ ), whole blood clot lysis index (WBCLI, $A_{60} /$ $\mathrm{MA} \cdot 100$ [\%], and whole blood clot lysis time (F [min]) (fig. 2).

The surgical procedure is divided into three stages, according to distinctive anatomic and physiologic alterations at each stage. The preanhepatic stage (stage 1), begins at induction of anesthesia and ends at hepatectomy. The anhepatic stage (stage 2) is the period between hepatectomy and reperfusion of the graft liver by portal venous blood. The postanhepatic stage (stage 3 ) lasts from reperfusion of the graft liver to the end of surgery.

\section{Evaluation OF FIBRINOLYSIS}

Blood samples ( $15 \mathrm{ml}$ each) were obtained from an unheparinized indwelling arterial catheter for coagulation monitoring at the following times: before induction of anesthesia; $30 \mathrm{~min}$ into surgery; thereafter every $2 \mathrm{~h}$ or after infusion of every 61 of fluid volume; $5 \mathrm{~min}$ before removing the liver; $5 \mathrm{~min}$ into the anhepatic stage; 30 $\min$ into the anhepatic stage; $5 \mathrm{~min}$ before reperfusion of the graft liver; 5 min after reperfusion of the graft liver, $30 \mathrm{~min}$ after reperfusion of the graft liver; and thereafter every $\mathbf{2} \mathrm{h}$ or after every $\mathbf{6 l}$ of fluid infusion.

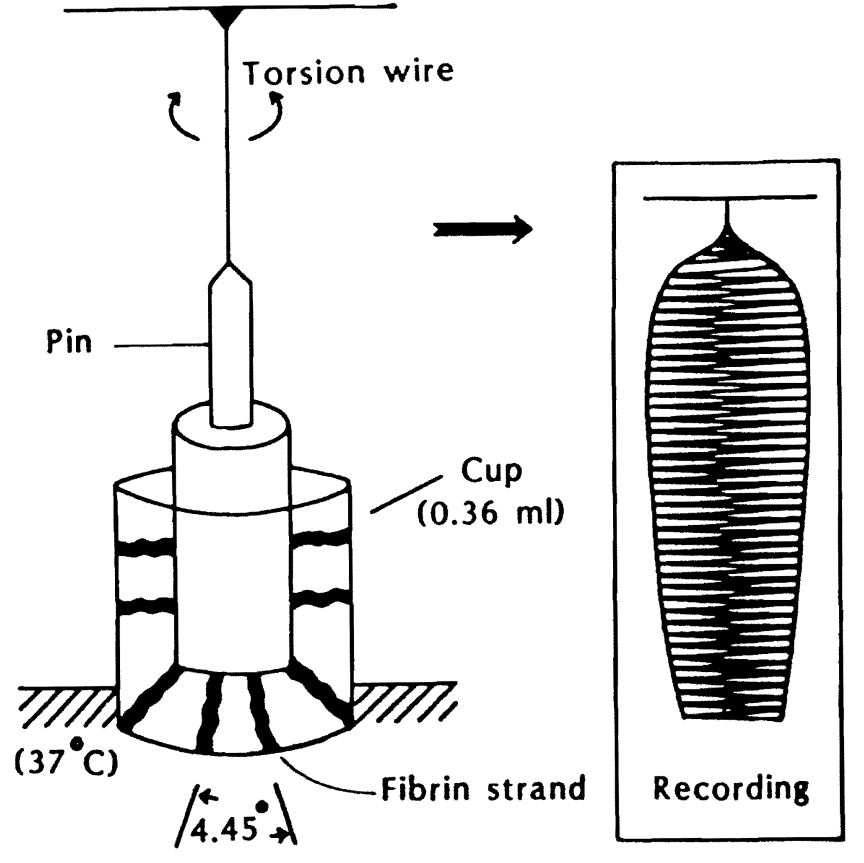

FiG. 1. Schematic diagram of thrombelastography.

The blood samples were tested by TEG and coagulation profile. Whole blood $(0.36 \mathrm{ml})$ was used for TEG tests, ${ }^{9}$ and recordings began $4 \mathrm{~min}$ after blood sampling. Measured coagulation profile variables included platelet count; prothrombin time (PT); activated partial thromboplastin time (aPTT); thrombin time (TT); reptilase time (RT); level of factors I, II, V, VII, VIII, IX, X, XI, and XII; fibrin degradation products (FDP); ethanol gel test; protamine gel test; and euglobulin lysis time (ELT). ${ }^{10-12} \mathrm{Fi}$ brinolysis was defined to be present when complete whole blood clot lysis was observed within $3 \mathrm{~h}$ or when whole blood clot lysis index (WBCLI) was less than $80 \%$.

\section{Evaluation of EACA IN VITRO}

When blood clot lysis time (F) was less than $180 \mathrm{~min}$ or $5 \mathrm{~min}$ after reperfusion of the graft liver, two blood

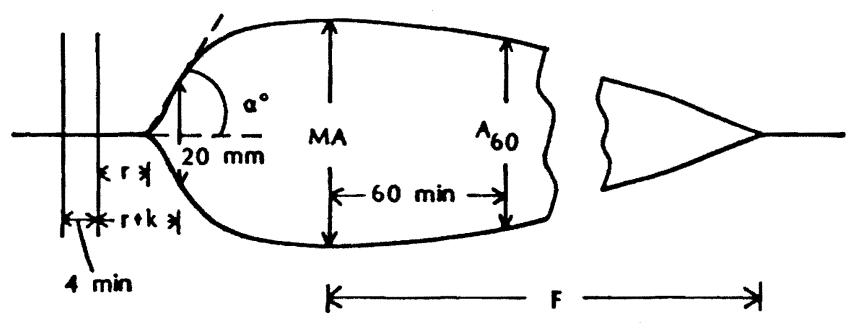

Fic. 2. Variables measured by thrombelastography and their normal values: $\mathbf{r}=$ reaction time $(\mathrm{min}) ; \mathbf{r}+\mathbf{k}=$ coagulation time $(\min ) ; a$ $=$ clot formation rate $\left({ }^{\circ}\right) ; \mathrm{MA}=$ maximum amplitude $(\mathrm{mm}) ; A_{\infty}=$ amplitude $60 \mathrm{~min}$ after maximum amplitude $(\mathrm{mm}) ; \mathrm{F}=$ whole blood clot lysis time $(\mathrm{min}) ;$ and $\mathrm{WBCLI}=$ whole blood clot lysis index $\left(\mathrm{A}_{\mathrm{ad}}\right.$ MA $\cdot 100, \%)$. 
TABLE 1. Thrombelastographic Variables and Coagulation Profile in the Preoperative Period and in the Most Active Fibrinolytic Stage in 80 Patients Who Showed Fibrinolysis

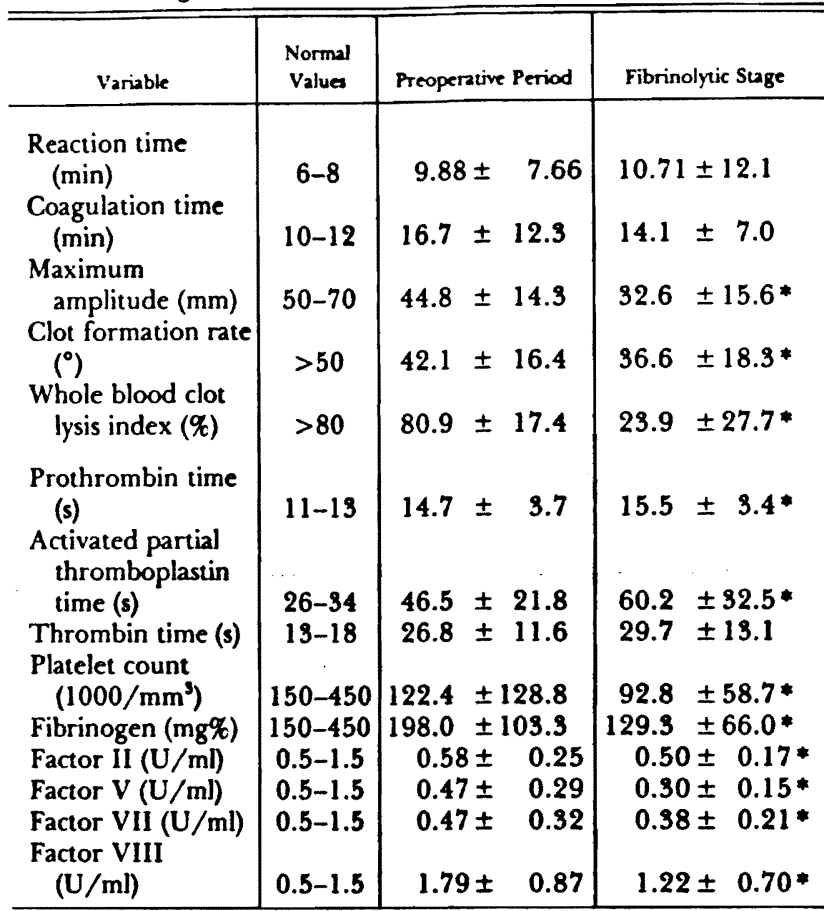

Values are means \pm SD.

$* P<0.05$ compared with preoperative values.

samples were tested by TEG; one sample $(0.33 \mathrm{ml})$ was treated with $0.03 \mathrm{ml}$ of EACA (1\% solution), and the other $(0.36 \mathrm{ml})$ was untreated blood. The TEG variables measured in EACA-treated blood and in untreated blood were compared.

\section{Clinical Application of EACA}

When severe fibrinolysis ( F $<120 \mathrm{~min}$ ) and generalized oozing occurred during surgery, and fibrinolysis was prevented in vitro in EACA-treated blood, as evidenced by an increase in whole blood clot lysis time (F), a single 1$\mathrm{g}$ dose of EACA was administered intravenously to the patient. However, when active fibrinolysis occurred near the anhepatic stage (from $\mathbf{3 0}$ min before removal of the native liver to the completion of the hepatic arterial anastomosis after reperfusion of the graft liver) EACA was not given, to avoid possible clot formation in the venovenous bypass circuit. TEG and coagulation profile variables were observed to assess the clinical effectiveness of the antifibrinolytic therapy. To evaluate the possible microcirculatory thrombotic effects of EACA, postoperative renal function was assessed by measuring blood urea nitrogen and serum creatinine levels for 7 postoperative days.

All measured variables are presented as mean $\pm \mathrm{SD}$. Data were analyzed by linear regression, nonparametric
Wilcoxon test for paired data, and analysis of variance of repeated measures, and specific differences were assessed with the Student-Newman-Keuls test. $P<0.05$ was considered statistically significant.

\section{Results}

\section{Evaluation OF FibRINOLYTIC ACTIVITY}

Seventy-nine patients received 97 liver transplants during the study period; 18 operations were retransplantations. On 82 occasions, a complete preoperative coagulation profile was available: average PT was $15.0 \pm 3.9$ $\mathrm{s}$; aPTT, $46.4 \pm 23.4 \mathrm{~s}$; TT, $26.8 \pm 11.4 \mathrm{~s}$; RT, 24.6 $\pm 7.6 \mathrm{~s} ;$ platelet count, $133,800 \pm 142,700 / \mathrm{mm}^{3}$. All coagulation factors except fibrinogen $(199.5 \pm 115.4 \mathrm{mg} \%)$ and factor VIII $(1.78 \pm 0.81 \mathrm{U} / \mathrm{ml})$ were $30-60 \%$ of normal. Preoperative TEG values were available in all 97 patients; they showed prolonged reaction time $(r, 10.2$ $\pm 7.7 \mathrm{~min}$ ) and coagulation time $(r+k, 17.8 \pm 13.5 \mathrm{~min})$, decreased maximum amplitude (MA, $44.6 \pm 14.5 \mathrm{~mm}$ ), and decreased clot formation rate $\left(\alpha, 40.9 \pm 17.0^{\circ}\right)$. Preoperative fibrinolysis was demonstrated by TEG as a whole blood clot lysis index (WBCLI) of less than $80 \%$ in 29 patients (30.5\%) and complete whole blood clot lysis within $3 \mathrm{~h}$ in 4 patients. In 13 of 84 patients (15.5\%), ELT was $1 \mathrm{~h}$ or less preoperatively.

Intraoperatively, 17 patients $(17.5 \%)$ showed no sign of fibrinolysis (group 1), while 80 patients $(82.5 \%$ ) showed signs of fibrinolysis (WBCLI $<80 \%$ or F $<180 \mathrm{~min}$ ) in at least one blood sample during the surgical procedure (group 2). The pre- and intraoperative coagulation profiles of patients in group 1 were not different from those in group $2(P=0.20)$. In group 2 , fibrinolysis was most severe during the preanhepatic stage in 21 patients (26.2\%), during the anhepatic stage in 19 patients (23.8\%), and during the postanhepatic stage in 40 patients (50\%). Fibrinolysis was most severe immediately after reperfusion of the graft liver in 33 patients. The duration of fibrinolysis (WBCLI < 80\%) was measured from its appearance to its disappearance on the TEG recording. Mean duration was $216 \pm 136 \mathrm{~min}$; duration was less than $4 \mathrm{~h}$ in 44 patients and $4-8 \mathrm{~h}$ in 36 patients. No patient demonstrated fibrinolysis at the end of surgery. In table 1, the coagulation profile and TEG values in the most active fibrinolytic stage (defined by the minimum WBCLI) for group 2 patients are compared with preoperative values. The most significant thrombelastographic changes were a decrease in MA from $44.8 \pm 14.3$ to $32.6 \pm 15.6 \mathrm{~mm}$, in clot formation rate $(\alpha)$ from $42.1 \pm 16.4$ to 36.6 $\pm 18.3^{\circ}$, and, in WBCLI, from $80.9 \pm 17.4$ to 23.9 $\pm 27.7 \%$. Platelet count and all coagulation factor levels decreased. The frequency distribution of whole blood clot lysis time, ELT, FDP, and fibrin monomers is shown in 
TABLE 2. Intraoperative Changes in Whole Blood Clot Lysis Time, Euglobulin Lysis Time, Fibrin Degradation Products, and Fibrin Monomers in 68 Patients Who Showed Fibrinolysis

\begin{tabular}{l|c|c}
\hline \multirow{2}{*}{ Variable } & \multicolumn{2}{|c}{ Number of Patients } \\
\cline { 2 - 3 } & $\begin{array}{c}\text { Preoperative } \\
\text { Period }\end{array}$ & $\begin{array}{c}\text { Fibrinolytic } \\
\text { Stage }\end{array}$ \\
\hline W'hole blood clot lysis time & & \\
$0-60 \mathrm{~min}$ & 1 & 36 \\
$61-120 \mathrm{~min}$ & 0 & 25 \\
$121-180 \mathrm{~min}$ & 3 & 3 \\
$>180 \mathrm{~min}$ & 64 & 4 \\
Euglobulin lysis time & & \\
$0-60 \mathrm{~min}$ & 13 & 49 \\
$61-120 \mathrm{~min}$ & 7 & 4 \\
$>120 \mathrm{~min}$ & 48 & 15 \\
Fibrin degradation products & & 43 \\
$0 \mu \mathrm{g} / \mathrm{ml}$ & 55 & 7 \\
$10-40 \mu \mathrm{g} / \mathrm{ml}$ & 5 & 7 \\
$>40 \mu \mathrm{g} / \mathrm{ml}$ & 8 & 18 \\
Fibrin monomers & & 24 \\
0 & 56 & 33 \\
+ & 11 & 10 \\
++ & 1 & 1 \\
+++ & 0 & \\
\hline
\end{tabular}

Whole blood clot lysis time and euglobulin lysis time decreased, and level of fibrin monomers increased, during the fibrinolytic stage.

table 2. Whole blood clot lysis time (F) was less than 120 $\min$ in one patient preoperatively and in 61 patients at the most severe fibrinolytic stage $(P<0.05)$. The changes in ELT were similar. The number of patients who showed positive soluble fibrin monomers increased during the most severe fibrinolytic stage, but the increase in FDP was not significant. In group 2 patients, fibrinolysis measured as ELT did not correlate with whole blood clot lysis time (F) or whole blood clot lysis index (fig. 3).

\section{Evaluation OF EACA IN VITRO}

When fibrinolysis ( $F<180 \mathrm{~min}$ ) was observed and, 5 min after reperfusion of the graft liver, the TEG values in untreated blood were compared with those in EACAtreated blood $(n=74)$ (table 3, fig. 4). In treated blood, all TEG values improved: WBCLI increased from 48.9 $\pm 42.2 \%$ to $93.6 \pm 16.9 \%$, and whole blood clot lysis did not occur during the 5 -h observation period in all 74 cases.

\section{Clinical Application of EACA}

EACA $(1 \mathrm{~g})$ was administered intravenously to $20 \mathrm{pa}$ tients who had oozing from a previously dry surgical field and severe fibrinolysis $(\mathrm{F}<120 \mathrm{~min}$ ) that was reversed by EACA in vitro. EACA was given during the pre-anhepatic stage in five patients and after reperfusion of the graft liver in 15 patients. Preoperative coagulation profile and TEG values in patients given EACA were similar to those in patients not given EACA. TEG and coagulation

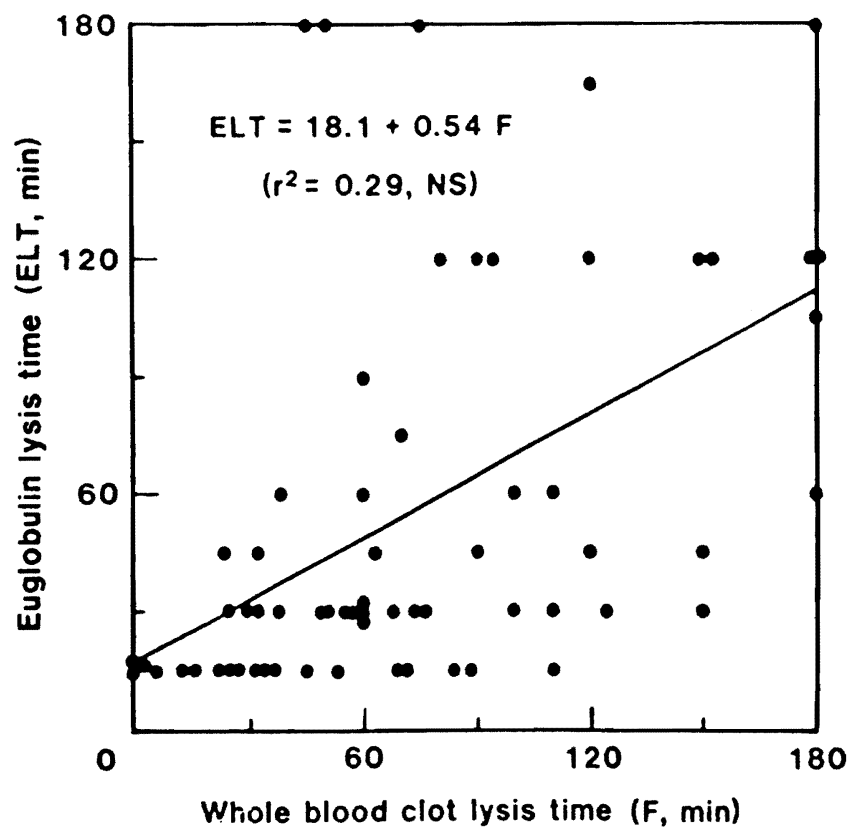

FIG. 3. Relation between whole blood clot lysis time (F) and euglobulin lysis time (ELT) in patients who demonstrated fibrinolysis. The correlation was poor $\left(r^{2}=0.29\right)$.

profile variables measured before and $10 \mathrm{~min}$ after the administration of EACA are shown in tables 4 and 5 and figure 4. The improvement in coagulability is shown by increases in MA and WBCLI and whole blood clot lysis time (F) longer than $5 \mathrm{~h}$ in all patients. But EACA did not improve the coagulation profile significantly except for a moderate increase in ELT. In all patients given EACA, oozing from the surgical field stopped immediately, and whole blood clot lysis did not recur.

The clinical course of all patients was observed for thrombotic complications. Four patients suffered throm-

\begin{tabular}{|c|c|c|c|}
\hline Variable & $\begin{array}{l}\text { Normal } \\
\text { Values }\end{array}$ & $\begin{array}{l}\text { Untreated } \\
\text { Blood }\end{array}$ & $\begin{array}{l}\text { Blood Treated } \\
\text { with EACA }\end{array}$ \\
\hline $\begin{array}{l}\text { Reaction time } \\
\text { (min) } \\
\text { Coagulation time } \\
\text { (min) } \\
\text { Maximum } \\
\text { amplitude (mm) } \\
\text { Clot formation rate } \\
\text { ( }) \\
\text { Whole blood clot } \\
\text { lysis index (\%) } \\
\text { Whole blood clot } \\
\text { lysis time (min) }\end{array}$ & $\begin{array}{l}6-8 \\
10-12 \\
50-70 \\
>50 \\
>80 \\
>180\end{array}$ & $\begin{array}{r}9.6 \pm 5.4 \\
24.8 \pm 18.0 \\
33.0 \pm 14.9 \\
30.7 \pm 16.7 \\
48.9 \pm 42.2 \\
62.6 \pm 38.3\end{array}$ & $\begin{array}{c}8.1 \pm 4.2^{*} \\
19.2 \pm 8.2 * \\
40.3 \pm 15.4^{*} \\
36.4 \pm 17.1^{*} \\
93.6 \pm 16.9 * \\
>180 \dagger\end{array}$ \\
\hline
\end{tabular}

Values are mean \pm SD.

* $P<0.05$ compared with corresponding values in untreated blood. † Whole blood clot lysis time was greater than $180 \mathrm{~min}$ in all tests. 


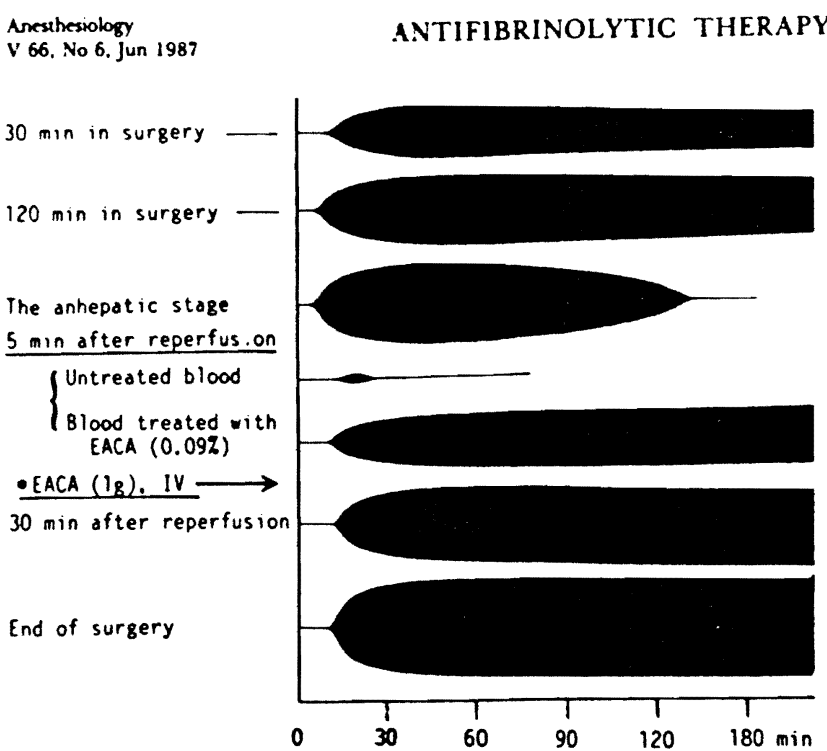

FIG. 4. Thrombelastographic patterns in a patient undergoing liver transplantation. t-aminocaproic acid (EACA, 1 g) was administered intravenously when severe fibrinolysis was observed on thrombelastography, generalized oozing occurred in a previously dry surgical field and EACA treated fibrinolysis in vitro.

botic or hemorrhagic complications intra- or postoperatively: two pulmonary emboli, one hepatic arterial thrombosis of the grafted liver, and one subarachnoidal hemorrhage. None of these patients had received EACA. Postoperative renal function measured by blood urea nitrogen and serum creatinine levels was similar in the two groups for 7 days.

TABlE 4. Thrombelastographic Variables and Coagulation Profile in Patients who Received t-aminocaproic Acid (EACA, 1 g)

\begin{tabular}{|c|c|c|}
\hline Variable & Before EACA & 10 Min After EACA \\
\hline $\begin{array}{l}\text { Reaction time (min) } \\
\text { Coagulation time (min) } \\
\text { Maximum amplitude (mm) } \\
\text { Clot formation rate }\left({ }^{\circ}\right) \\
\text { Whole blood clot lysis } \\
\text { index (\%) } \\
\text { Whole blood clot lysis time } \\
\text { (min) }\end{array}$ & $\begin{array}{r}11.1 \pm 11.3 \\
21.1 \pm 22.9 \\
35.9 \pm 12.8 \\
37.6 \pm 19.4 \\
28.5 \pm 29.5 \\
75.7 \pm 34.6\end{array}$ & $\begin{aligned} & 8.3 \pm 3.8 \\
& 14.2 \pm 6.4 \\
& 49.8 \pm 5.7^{*} \\
& 44.8 \pm 13.6 \\
& 94.8 \pm 7.4^{*} \\
&>180 \dagger\end{aligned}$ \\
\hline $\begin{array}{l}\text { Prothrombin time (s) } \\
\text { Activated partial } \\
\text { thromboplastin time (s) } \\
\text { Thrombin time (s) } \\
\text { Platelet count (1000/mm') } \\
\text { Fibrinogen }(\mathrm{mg} g) \\
\text { Factor II }(\mathrm{U} / \mathrm{mI}) \\
\text { Factor V }(\mathrm{U} / \mathrm{ml}) \\
\text { Factor VII }(\mathrm{U} / \mathrm{ml}) \\
\text { Factor VIII }(\mathrm{U} / \mathrm{ml})\end{array}$ & $\begin{array}{r}16.0 \pm 1.9 \\
62.5 \pm 23.1 \\
30.4 \pm 10.9 \\
132.6 \pm 80.5 \\
128.2 \pm 48.1 \\
0.46 \pm 0.11 \\
0.22 \pm 0.08 \\
0.33 \pm 0.10 \\
0.98 \pm 0.67\end{array}$ & $\begin{array}{r}16.3 \pm 1.7 \\
57.6 \pm 15.0 \\
30.1 \pm 10.9 \\
113.1 \pm 36.5 \\
124.2 \pm 38.9 \\
0.45 \pm 0.11 \\
0.20 \pm 0.06 \\
0.34 \pm 0.09 \\
0.91 \pm 0.62\end{array}$ \\
\hline
\end{tabular}

Values are mean \pm SD.

- $P<0.05$ compared with the corresponding values before EACA. t Whole blood dot lysis time was greater than $180 \mathrm{~min}$ in all oc.

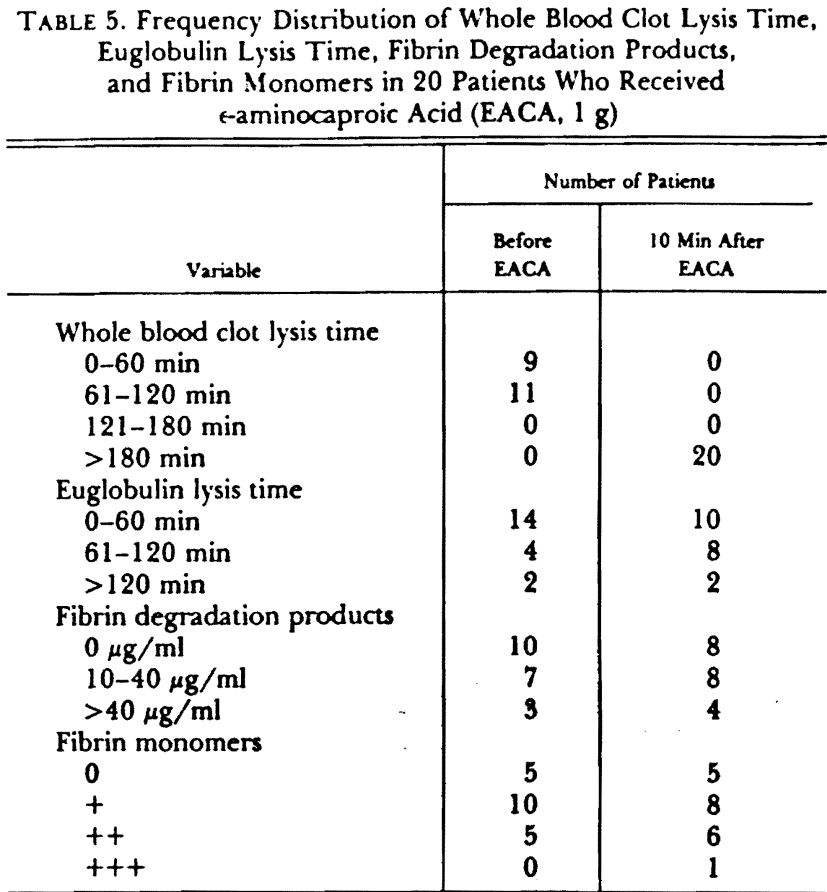

Whole blood clot lysis time and euglobulin lysis time increased 10 min after EACA administration.

\section{Discussion}

Fibrinolysis is well recognized in patients with acute and chronic liver disease. Active fibrinolysis, manifest as weak blood clots or generalized oozing that necessitates continuous blood transfusion, is the most striking feature of the coagulation system during liver transplantation. Cirrhotic patients are prone to fibrinolysis even after relatively benign stimuli, ${ }^{13}$ and show an exaggerated fibrinolytic response to vasoactive substances. Delayed hepatic clearance of circulating plasminogen activators, defective synthesis or decreased levels of naturally occurring inhibitors, and activation of protein $\mathbf{C}$ have been postulated as responsible for the fibrinolysis in patients with liver cirrhosis. ${ }^{14-17} \pi$ However, it is controversial whether the fibrinolytic activity in patients with liver disease is primary or secondary to disseminated intravascular coagulation, mainly because of difficulties in differentiation by laboratory tests. ${ }^{18}$

In our experience, fibrinolysis occurring during liver transplantation has appeared to be primary in origin. Prolonged PT and aPTT, thrombocytopenia, hypofibrinogenemia, decrease in coagulation factors, positive fibrin degradation products, positive soluble fibrin monomers, and decrease in antithrombin III are the typical laboratory

I Comp PC, Esmon CT: Initiation of clot lysis in plasma by activated protein C (Abstract). Circulation 58:II-210, 1978 
findings in patients with disseminated intravascular coagulation. ${ }^{19}$ But it is not unusual to observe similar changes before and during liver transplantation without signs of fibrinolysis, as evidenced by similar levels of coagulation factors in patients with and without fibrinolysis. This poor coagulation state is due mainly to poor hepatocellular synthetic function and intraoperative dilution. During liver transplantation, only minimal quantities of circulating fibrin monomers and fibrin degradation products have been detected during fibrinolysis, ${ }^{20}$ although high levels of fibrin monomers and fibrin degradation products are frequently seen in disseminated intravascular coagulation. In this study, FDP level was relatively low during the fibrinolytic stage, and use of EACA did not decrease FDP level. Levels of fibrin degradation products can be high during liver transplantation, but this usually occurs toward the end of surgery, when fibrinolysis is no longer seen, possibly from reabsorption of extravascular blood and fibrinous exudate or delayed hepatic reticuloendothelial clearance of fibrin degradation products. ${ }^{21}$ In secondary fibrinolysis, hypercoagulation precedes hypocoagulation. In our experience, a normal or hypercoagulable state has been very rare in patients receiving liver transplants, having occurred only in a few patients with neoplasms or Budd-Chiari syndrome. Furthermore, the hypocoagulable state commonly seen in the preoperative period in our patients responds readily to replacement therapy.

Most important, Lewis et al. observed a disproportional decrease in factors $\mathrm{V}$ and VIII:C during the anhepatic stage and upon reperfusion of the graft liver, and suggested that these factors might be destroyed selectively by circulating plasmin in the process of active fibrinolysis. ${ }^{20}$ They found that the plasminogen level decreased moderately during the anhepatic stage, while the antiplasmin level decreased precipitously during the anhepatic stage and after reperfusion. Since fibrinolysis occurs when the balance between activators and inhibitors is impaired; the occurrence of primary fibrinolysis during liver transplantation is not surprising.

In the present study, although fibrinolysis was most dramatic upon reperfusion of the graft liver, it was seen during the preanhepatic and anhepatic stages as well. Fibrinolysis during the preanhepatic and anhepatic stages may be caused by decreased clearance of circulating activated plasminogen, release of tissue and vascular plasminogen activators, and decreased synthesis of inhibitors. However, the "explosive" fibrinolysis seen early in the postanhepatic stage may be caused by substances originating from the donor liver. Because it occurs within 5 min after reperfusion of the graft liver, sudden quantitative changes in coagulation factors and fibrinolytic proteins in the recipients are unlikely to have occurred. Although the graft is preserved hypothermically in a solution with intracellular composition, changes in cellular membrane permeability are expected to occur. The release from the donor liver of substances activating plasminogen or suppressing inhibitors of fibrinolysis may cause explosive fibrinolysis after reperfusion.

Although fibrinolysis occurs frequently during hepatic surgery, it has been treated only sporadically. Grossi et al. used EACA in patients who developed marked fibrinolysis and severe oozing during portacaval shunt procedures, and it appeared to prevent fibrinolysis and bleeding. ${ }^{22}$ In a study of animals receiving liver grafts, EACA did not seem to prevent fibrinolysis. ${ }^{23}$ Flute $e t$ al. reported a possible beneficial role of EACA in liver transplantation patients. ${ }^{7}$ Pharmacologic antifibrinolytic therapy was instituted by von Kaulla et al., who reported giving EACA $(1 \mathrm{~g} / \mathrm{h})$ to three patients during liver transplantation and several days postoperatively. ${ }^{6}$ EACA appeared to stop fibrinolysis in all three patients, but one died intraoperatively with uncontrollable bleeding. Deep venous thrombosis developed in one patient and pulmonary emboli in the other. After observing a high incidence of hypercoagulable state and pulmonary emboli in their patients with and without EACA therapy, von Kaulla et al. suggested that the fibrinolysis during liver transplantation was a self-limiting process caused by organ systems other than the liver, and that pharmacologic manipulation of the coagulation system during liver transplantation was not necessary and might be harmful. However, thrombosis in major vessels is not uncommon in patients with liver disease, ${ }^{24}$ and all their adult patients had neoplasms, with which a hypercoagulable state is known to be associated. If the thrombotic complications were associated with antifibrinolytic therapy, they could have been caused by a residual effect of relatively large doses of EACA (100 mg/ $\mathrm{kg}$ ), which may have interfered with the delicate balance between coagulation and fibrinolysis in the postoperative period.

The controversy surrounding clinical use of EACA stems from several difficulties in antifibrinolytic therapy. First, the indications for antifibrinolytic therapy have been unclear. In surgical patients, EACA has been used in cases of severe generalized oozing with short ELT and bleeding from untraumatized sites. However, generalized bleeding is not necessarily caused by fibrinolysis, and ELT reflects only the activity of plasminogen. Although ELT is known to correlate with whole blood clot lysis time, a poor correlation was found in this study. ELT measures only the activity of plasminogen, not other substances affecting the fibrinolytic system, such as plasmin and inhibitors. A balance between plasminogen activators and its inhibitors may be a better indicator of fibrinolysis. ${ }^{25}$

Second, monitoring of fibrinolysis has been inadequate. In the present study, TEG was used to monitor fibrinolysis. TEG demonstrates the net balance of the fibrinolytic 
system, including activators and inhibitors, which more accurately reflects in vivo conditions. TEG has been shown to be a reliable technique and to correlate with the coagulation profile. ${ }^{26}$ Its selective sensitivity and reliability as a test for fibrinolysis have been demonstrated by von Kaulla in a study of serial changes in whole blood clot lysis time after administration of pyrogenic lipopolysaccharide in humans. ${ }^{27}$ Recently, Summaria et al. showed a progressive decrease in whole blood clot lysis time when incremental doses of the plasminogen activator, $\beta$-chainstreptokinase, were added to whole blood. ${ }^{28}$ Streptokinase that was given to patients with thrombotic conditions showed similar changes in whole blood clot lysis time.

Third, EACA therapy may lead to thrombotic complications. Although rapid fibrinolysis, ranging from no clotting at all to a rapid total blood clot lysis that accompanied massive intraoperative intragastric bleeding, was observed frequently, and the effectiveness of antifibrinolytic therapy was demonstrated repeatedly in vitro, we did not use EACA in patients in our early experience because we feared possible thrombotic complications, ${ }^{29}$ such as thrombosis of the portal vein, inferior vena cava, or hepatic artery or pulmonary emboli. Microemboli in the renal glomerular capillaries may impair complex postoperative renal function. In this study, hemorrhagic or thrombotic complications developed intra- or postoperatively in four patients, but they had not received EACA. Two of these patients had massive pulmonary emboli intraoperatively, in the beginning of the anhepatic stage using veno-veno bypass. Their pre- and intraoperative coagulation profiles and TEG patterns were poor, and it appears that migration of preexisting thrombi in the portal vein or deep venous system occurred. Subarachnoid hemorrhage was diagnosed postoperatively in one patient, but the intracranial pathology appeared to have been present preoperatively. One patient had developed a postoperative hepatic arterial thrombosis, which is not uncommon after major vascular surgery.

Fourth, the optimal clinical dose of EACA has not been identified. McNicol et al. recommended oral or intravenous administration of $1 \mathrm{~g}$ EACA every hour after a priming dose of 4-5 $\mathrm{g}$ to achieve an EACA plasma level of $13 \mathrm{mg} \%{ }^{30}$ However, this dosage is based on complete inhibition of fibrinolysis in vilro, and the individual clinical situation should dictate its own dose schedule. The fibrinolytic process during liver transplantation was severe, although transient (less than $8 \mathrm{~h}$ ), and, when stopped in the initial stage with a minimal dose of EACA, progressive coagulopathy was prevented without untoward effect. EACA is almost completely eliminated in urine within 6 $h$, and one would expect the residual effect of $1 \mathrm{~g}$ of EACA to be negligible in the latter part of surgery and the postoperative period. In the present study, the dose of EACA used for in vitro evaluation of fibrinolysis was fivefold larger than the clinical dose. McNicol et al. showed that a larger dose of EACA (130 mg\%) was needed to inhibit plasminogen activity in zitro, ${ }^{30}$ while Lerner et al. found that a dose four times smaller than the in vitro dose was sufficient to arrest fibrinolysis during open-heart surgery.** In this study, the effectiveness of EACA was tested in vitro. EACA accelerates coagulation by shifting the equilibrium away from fibrinolysis. But, in healthy subjects with minimal fibrinolysis, the changes in reaction time and coagulation time are minimal, and changes in fibrinolysis time and whole blood clot lysis index are not seen (Kang YG, unpublished data). EACA was used only when certain criteria were met: severe fibrinolysis was seen on TEG, EACA halted fibrinolysis in vitro, and generalized oozing occurred from a previously dry surgical field. Therefore, the indications for EACA use were not only its effectiveness in vitro, but also the demonstration of severe fibrinolysis by both laboratory techniques and clinical signs.

This study was not designed to evaluate the clinical effectiveness of EACA in a double-blind fashion, because mild fibrinolysis may not require treatment and withholding beneficial treatment from a patient with severe fibrinolysis is not justified. Evaluating the clinical effectiveness of antifibrinolytic therapy in terms of transfusion requirements, particularly during liver transplantation, is difficult. The transfusion requirement is influenced by many factors: preoperative status of the coagulation system including its vascular phase, difficulties in surgery, technical skill of the surgeons, adequacy of blood replacement and pharmacologic therapy, and quality of the donor organ. Therefore, blood loss was not compared between patients who did and who did not receive EACA.

The present study demonstrated the safety of EACA therapy in a large series of patients undergoing liver transplantation. First, thrombelastographic monitoring of the coagulation system, which monitors the balance of fibrinolytic activity and the activity of inhibitors, clearly identified any imbalance in the fibrinolytic system. Second, the drug was administered only when fibrinolytic activity was demonstrated by TEG, EACA was proven effective by TEG in EACA-treated blood, and generalized oozing from a previously dry surgical field occurred. Third, a very small single dose $(1 \mathrm{~g})$ was used in this study, and was clinically effective in all cases. We do not know whether an even smaller dose might be equally effective during liver transplantation, or whether the small dose we used is suitable for other patients requiring antifibrinolytic therapy. Fourth, it is interesting that major vascular thrombotic complications occurred only in patients

** Lerner RG, Reed GE, Nelson JC, Pooley R, Moggio R, Somberg E, Praeger P: Rapid monitoring and treatment of fibrinolysis associated with heart surgery (Abstract). Circulation 66:11-319, 1982 
not given EACA. Although blood urea nitrogen and serum creatinine level are crude assessments of renal function, and hepatorenal syndrome and cyclosporine nephrotoxicity could have affected postoperative renal function, the values were similar in treated and untreated patients. Subnormal levels of coagulation factors and platelets are common in patients receiving liver transplants, and a transient arrest of fibrinolysis is unlikely to cause thrombosis.

In summary, most patients undergoing liver transplantation demonstrated active fibrinolysis, evidenced by TEG monitoring and shortened ELT. EACA $(1 \mathrm{~g})$ was given to patients who showed active fibrinolysis and generalized oozing when the drug was proven effective by TEG in EACA-treated blood in vitro. It effectively treated fibrinolysis in all cases, and complications associated with its use were not observed.

The authors thank Ms. Lisa Martin, Mr. Steven Miller, and Mr. Mark Zapp for technical assistance; Ms. Lisa Cohn for editorial help; and The Hellige Company of Germany and the Hemoscope Corporation, Skokie, Illinois, for the donation of equipment.

\section{References}

1. Bontempo FA, Lewis JH, Van Thiel DH, Spero JA, Ragni MV, Butler P, Israel L, Starzl TE: The relation of preoperative coagulation findings to diagnosis, blood usage, and survival in adult liver transplantation. Transplantation 39:532-536, 1985

2. Groth CG, Pechet L, Starzl TE: Coagulation during and after orthotopic transplanation of the human liver. Arch Surg 98: 31-34, 1969

3. Kang YG, Martin DJ, Marquez JM, Lewis JH, Bontempo FA, Shaw BW Jr, Starzl TE, Winter PW: Intraoperative changes in blood coagulation and thrombelastographic monitoring in liver transplantation. Anesth Analg 64:888-896, 1985

4. Shaw BW Jr, Martin DJ, Marquez J, Kang YG, Bugbee AC Jr, Iwatsuki S, Griffith BP, Bahnson HT, Starzl TE, Hardesty RL: Venous bypass in clinical liver transplantation. Ann Surg 200: 524-534, 1984

5. Groth CG: Changes in coagulation, Experience in Hepatic Transplanation. Edited by Starzl TE. Philadelphia, WB Saunders, 1969, pp' 159-175

6. Von Kaulla KN, Kaye H, Von Kaulla E, Marchioro TL, Starzl TE: Changes in blood coagulation, before and after hepatectomy or transplantation in dogs and man. Arch Surg 92:7179, 1966

7. Flute PT, Rake MO, Williams R, Seaman MJ, Calne RY: Liver transplantation in man-IV, haemorrhage and thrombosis. $\mathrm{Br}$ Med J 3:20-23, 1969

8. Sassano JV: The rapid infusion system, Hepatic Transplantation: Anesthetic and Perioperative Management. Edited by Winter PW, Kang YG. New York, Praeger Publishers, 1986, pp 120134

9. De Nicob P. Thrombehastography. Springfield, Charles C Thomas Publisher, 1957, pp 5-27

10. Lewis JH: Coagulation defects. JAMA 178:1014-1020, 1961
11. Lewis JH: Hemostasis and hemorrhage. Sci Clin 1:1-66, 1971

12. Lewis JH, Spero JA, Hasiba U: Diagnostic methods: laboratory tests, Bleeding Disorders. Garden City, Medical Exam Publishing Co., Inc., 1978, pp 22-34

13. Das PC, Cash JD: Fibrinolysis at rest and after exercise in hepatic cirrhosis. $\mathrm{Br}$ J Haematol 17:431-443, 1969

14. Fletcher AP, Biederman O, Moore D, Alkjaersig N, Sherry S: Abnormal plasminogen-plasmin system activity (fibrinolysis) in patients with hepatic cirrhosis: Its cause and consequences. J Clin Invest 43:681-695, 1964

15. Aoki N, Yamanaka $\mathrm{T}$ : The $\alpha 2$-plasmin inhibitor levels in liver disease. Clin Chim Acta 84:99-105, 1978

16. Tygat $G$, Collen $D$, De Verker $R$, Verstraete $M$ : Investigations on the fibrinolytic system in liver cirrhosis. Acta Haematol (Basel) 40:265-274, 1968

17. O'Connel RA, Grossi CE, Rousselot LM: Role of inhibitors of fibrinolysis in hepatic cirrhosis. Lancet 990-991, 1964

18. Bloom $\mathrm{AL}$ : Intravascular coagulation and the liver. $\mathrm{Br} \mathrm{J}$ Haematol 30:1-7, 1975

19. Spero JA, Lewis JH, Hasiba U: Disseminated intravascular coagulation, Findings in 346 patients. Thromb Haemost 43:2833, 1980

20. Lewis JH, Bontempo FA, Kang YG, Spero JA, Ragni VM, Stard TE: Intraoperative coagulation changes in liver transplantation, Hepatic Transplantation: Anesthetic and Perioperative Management. Edited by Winter PM, Kang YG. New York, Praeger Publishers, 1986, 142-150

21. Herold R, Straub PW: Acute hepatic necrosis of hepatitis and mushroom poisoning. The value of coagulation tests in their differentiation, prognostic assessment and pathogenesis. Helv Med Acta 37:5-24, 1973-1974

22. Grossi CE, Rousselot LM, Panke WF: Coagulation defects in patients with cirrhosis of the liver undergoing portasystemic shunts. Am J Surg 104:512-525, 1962

23. Pechet L, Groth CG, Daloze PM: Changes in coagulation and fibrinolysis after orthotopic canine liver homotransplanation. J Lab Clin Med 73:91-102, 1969

24. Oka $\mathrm{K}$, Tanaka $\mathrm{K}$ : Intravascular coagulation in autopsy cases with liver diseases. Thromb Haemost 42:564-570, 1979

25. Pizzo SV, Fuchs HE, Doman KA, Petruska DB, Berger H Jr: Re lease of tissue plasminogen activator and its fast-acting inhibitor in defective fibrinolysis. Arch Intern Med 146:188-191, 1986

26. Zuckerman L, Cohen L, Vagher JP, Woodward E, Caprini JA. Comparison of thrombelastography with common coagulation tests. Thromb Haemost 46:752-756, 1981

27. von Kaulla KN: Continuous automatic recording of fibrin formation and fibrinolysis: A valuable tool for coagulation re search.J Lab Clin Med 49:304-312, 1957

28. Summaria L, Sandersara J, Yang G, Vagher JP, Caprini JA: Invitro comparison of fibrinolytic activity of plasminogen activators using a thrombelastographic method: In-vivo evaluation of the $\beta$-chain-streptokinase complex in the dog model using pre-titrated doses. Thromb Haemost 56:71-79, 1986

29. Ratnoff OD: Epsilon aminocaproic acid-a dangerous weapon. $\mathbf{N}$ Engl J Med 280:1124-1125, 1969

30. McNicol GP, Fletcher AP, Alkjaersig N, Sherry S: The absorption, distribution, and excretion of e-aminocaproic acid following oral or intravenou administration to man. J Lab Clin Med 59: 15-24, 1962 